OPEN ACCESS

Edited by:

Jerome Mallefet,

Catholic University of Louvain,

Belgium

Reviewed by:

Yuichi Oba,

Chubu University, Japan

Les Watling,

University of Hawaii at Mānoa,

United States

*Correspondence:

Anderson G. Oliveira

anderson.garbuglio@usp.br

Specialty section:

This article was submitted to

Marine Biology,

a section of the journal

Frontiers in Marine Science

Received: 22 December 2020

Accepted: 25 January 2021

Published: 18 February 2021

Citation:

Moraes GV, Hannon MC,

Soares DMM, Stevani CV, Schulze A

and Oliveira AG (2021)

Bioluminescence in Polynoid Scale

Worms (Annelida: Polynoidae).

Front. Mar. Sci. 8:643197.

doi: 10.3389/fmars.2021.643197

\section{Bioluminescence in Polynoid Scale Worms (Annelida: Polynoidae)}

\author{
Gabriela V. Moraes ${ }^{1}$, Mary Colleen Hannon², Douglas M. M. Soares ${ }^{3}$, \\ Cassius V. Stevani' ${ }^{3}$, Anja Schulze ${ }^{2}$ and Anderson G. Oliveira ${ }^{1 *}$ \\ ' Departamento de Oceanografia Física, Química e Geológica, Instituto Oceanográfico, Universidade de São Paulo, \\ São Paulo, Brazil, ${ }^{2}$ Department of Marine Biology, Texas A\&M University at Galveston, Galveston, TX, United States, \\ ${ }^{3}$ Departamento de Química Fundamental, Instituto de Química, Universidade de São Paulo, São Paulo, Brazil
}

Bioluminescence is widespread throughout the phylum Annelida and occurs in terrestrial and marine lineages. Among marine taxa, bioluminescence has been documented in eight families and anecdotally reported in six additional families. Although new bioluminescent systems have been recently described in annelids, there are still many other families whose light emission mechanisms have not been sufficiently studied. Some of these include luminescent species belonging to the Polynoidae family, also known as scale worms, whose iterations of dorsal elytra (scales) have the ability to emit intense light when stimulated. Depending on the degree of stimulation, some polynoids can autotomize these luminous elytra and posterior segments, which could potentially give them an advantage in evading attacks by predators. It is believed that Polynoidae bioluminescence is associated with a membrane enzyme known as "polynoidin," which was isolated during the early 1980s from Malmgrenia lunulata. However, the characterization and properties of this enzyme, as well as the chemical nature of its substrate or additional potential cofactors, have never been fully described and remain largely unknown. As such, this paper seeks to revisit previous research involving bioluminescence studies in Polynoidae, as well as the morphological, phylogenetic and ecological aspects related to this emission of light.

Keywords: marine annelids, Polynoidae, scale worm, photoprotein, polynoidin

\section{INTRODUCTION}

Bioluminescence is widely distributed across the tree of life, especially in marine organisms, with approximately 40 independent origins, and is present in 700 genera within 16 phyla (Herring, 1987; Moline et al., 2007; Haddock et al., 2010). Marine bioluminescent species are present in a wide variety of environments, being found from polar to tropical regions, in both surface areas and on the seabed (Harvey, 1957; Herring, 1987; Haddock et al., 2010). Of these bioluminescent organisms, the majority was observed within 200 and $800 \mathrm{~m}$ of depth, which includes the disphotic zone of the oceans (Widder, 2010). It is believed that $76 \%$ of the organisms of this zone have the ability to emit light (Haddock, 2006; Pieribone and Gruber, 2006; Martini and Haddock, 2017).

Bioluminescence has been reported in most of the major branches within the metazoan phylogeny, including some of the basal branches (ctenophores and cnidarians), ecdysozoans (arthropods), spiralians (mollusks and annelids), and deuterostomes (echinoderms and chordates). 
Among this wide range of taxa, annelid bioluminescence is one of the least studied. Verdes and Gruber (2017) released a comprehensive review of bioluminescence in annelids, focusing on the ecology and taxonomy of both marine and terrestrial worms. They presented 13 known families of annelids, eight of which are marine, with recorded descriptions of bioluminescent displays. These eight marine families include, among others, the well-studied, charismatic, displays from Chaetopteridae, Tomopteridae, and Syllidae. Only recently Kotlobay et al. (2019) and Mitani et al. (2019) reported the identification and purification of the luciferin and luciferase of the fireworm Odontosyllis. However, the biochemistry of bioluminescence in syllids is quite unique, especially when compared to the other related taxa. In fact, the process of light emission within annelids seems to be distinct in each family studied so far. One lesser mentioned family, Polynoidae, a family of scale worms, was highlighted as having green flashing light often used as sacrificial lures (Livermore et al., 2018). Polynoid scale worms are among the annelid taxa in which bioluminescence has been reported frequently (e.g., Nicol, 1953; Herrera, 1979; Plyuscheva and Martin, 2009). However, neither the molecular mechanisms nor the ecological significance are well understood. Polynoids have their dorsum partially or fully covered by pairs of elytra, or scales, and are found worldwide. Inside Polynoidae, bioluminescence has been reported in several species that have a layer of luminescent cells on the ventral epithelium of the elytra that emit a green light upon physical disturbance (Nicol, 1953; Plyuscheva and Martin, 2009), however, the behavioral or ecological function of this bioluminescence remains unknown (Bassot and Nicolas, 1995; Livermore et al., 2018).

Although the process of light emission in various bioluminescent organisms has been studied in recent years, the chemical nature of the substances involved in the bioluminescence of Polynoidae as well as the reactions involved in the process still remain unknown (Oba et al., 2017). In fact, in almost 50 years of biochemical studies involving different species of this family only a single photoprotein was isolated from Malmgrenia lunulata (formerly Harmothoe lunulata), the polynoidin, thus demonstrating the need to find out more about the bioluminescence of these organisms. Moreover, the morphological, phylogenetic and ecological aspects related the bioluminescence to Polynoidae will be addressed in this review.

\section{PHYLOGENY, ECOLOGY AND MORPHOLOGY OF THE POLYNOIDAE}

Although the phylogenetic relationships within the phylum Annelida are still not fully resolved, recent phylogenomic analyses agree that, apart from a few early branches in the annelid radiation, most species fall into one of the two major monophyletic clades, the Errantia or Sedentaria (Weigert et al., 2014; Figure 1). Bioluminescence has been reported in at least thirteen annelid families, including five families of clitellates (Verdes and Gruber, 2017). Clitellata is a monophyletic group in the Sedentaria and primarily composed of terrestrial and freshwater organisms such as earthworms and leeches.
Clitellates are traditionally contrasted with the "polychaetes," a paraphyletic assemblage including all of the mostly marine non-clitellate annelids.

This review focuses on the family Polynoidae, one of the taxa commonly referred to as "scale worms" or Aphroditiformia. The term scale worms is broadly applied to annelids covered with dorsal elytra, which are arranged in pairs on alternate segments, partially or fully covering the dorsum of these animals. Within the Aphroditiformia, six families are recognized, of which Polynoidae is the most speciose, including 10 subfamilies, 212 genera (Read and Fauchald, 2020) and at least 748 species (Hutchings, 2000). Currently, three studies have examined the phylogenetic relationships of the Aphroditiformia (Norlinder et al., 2012; Gonzalez et al., 2018; Zhang et al., 2018). They confirm the monophyly of the Aphroditiformia as well as that of the Polynoidae. Phylogenetic relationships among the polynoid subfamilies vary depending on the taxon sampling and analysis methods applied. While Zhang et al. (2018) recognize the two largest subfamilies, Polynoinae and Lepidonotinae, as monophyletic, Norlinder et al. (2012) and Gonzalez et al. (2018) did not confirm their monophyly. Polynoid taxonomy is in flux and some names of bioluminescent species have changed since their luminescent properties were first reported. A list with valid and previously used names was prepared to clarify any confusion (Supplementary Table 1).

Aphroditiformia in general, and Polynoidae, in particular, represent some of the most successful marine annelids. They can be found worldwide from the Tropics to the Antarctic (Hartman, 1978) and Arctic Seas (Britayev, 1991), from the intertidal to deep waters (Pettibone, 1989; Norlinder et al., 2012) occupying a wide range of habitats such as crevices in rocks, coral mounds, rubble, algal masses, seagrass roots, burrows, and tubes. Many polynoids live symbiotic (mutualistic or parasitic) with other invertebrates (Martin and Britayev, 1998, 2018). In fact, the luminous deepsea polynoid Neopolynoe chondrocladiae seems to be involved in a unique symbiotic relationship with carnivorous sponges of the Chondrocladia genus. Taboada et al. (2020) suggested that the worms might use bioluminescence to increase the chances of attracting prey and consequently, benefiting both partners. Polynoids are generally predators or scavengers that feed by everting their toothed pharynx (Hutchings, 2000).

The typical polynoid is oval, and dorsoventrally flattened with alternating pairs of elytra covering the dorsum (Figure 2). These elytra often have papillae, tubercles or ridges adorning the margins and are circular to renal form in shape (Rouse and Pleijel, 2001). In bioluminescent species, there are cells in the ventral epithelial layer of the scales called photocytes capable of emitting light (Bilbaut, 1980a; Fresneau et al., 1984; Wilson and Hastings, 1998). Alternating with the elytra are dorsal cirri, which project dorso-laterally and are sensory in nature. Polynoid parapodia (lateral extensions of the body used for locomotion) are biramous, typically with both noto- and neurochaete and associated supporting internal rods, called acicula. Chaetae are simple and usually have ridges or serrations. Typically, the ventral neurochaete are longer than the dorsal notochaete (Hutchings, 2000). Their head structures possess multiple sensory appendages such as median and paired antenna, palps, and one or two sets 


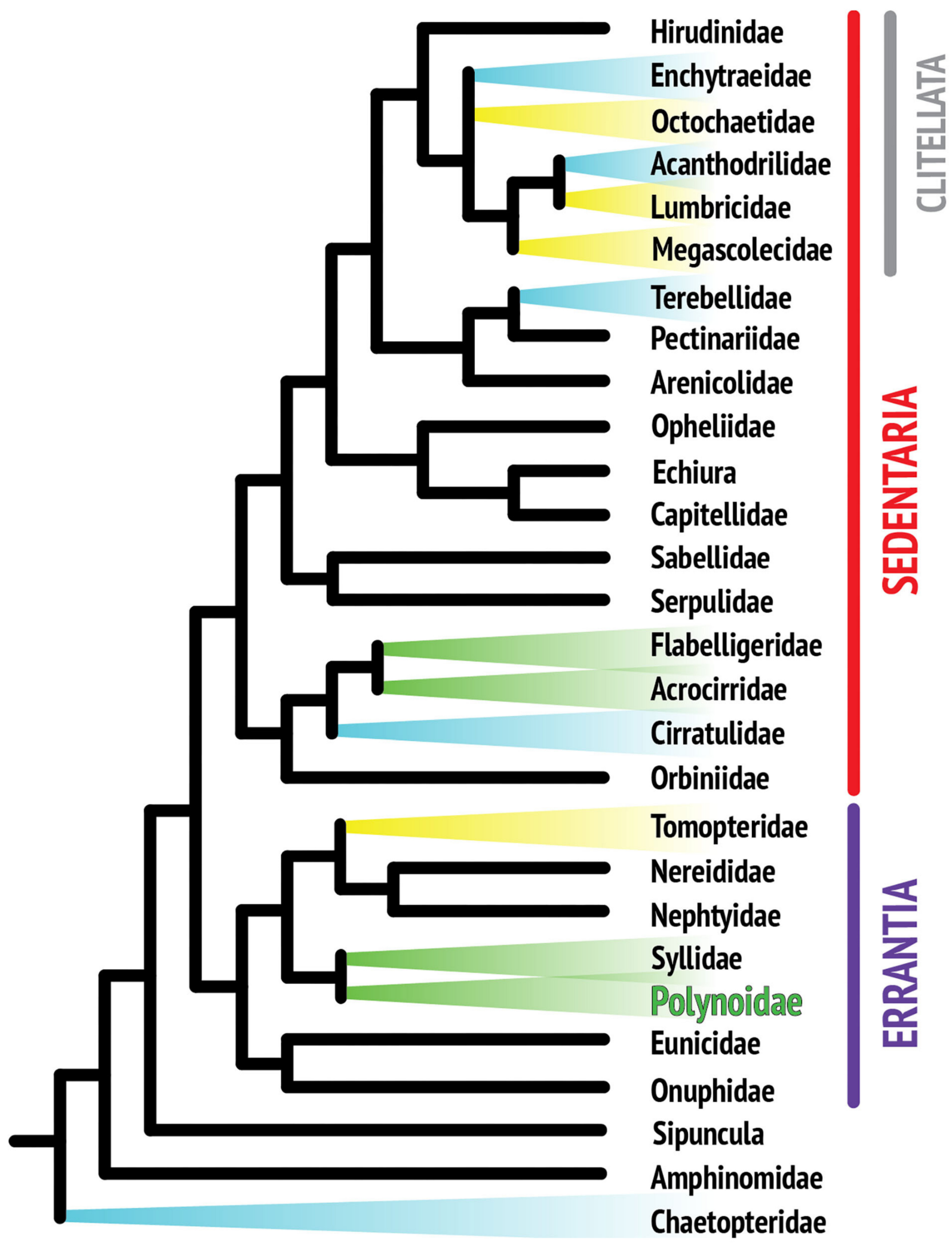

FIGURE 1 | Composite phylogenetic tree of annelid families based on recent phylogenetic and phylogenomic analyses. Note that not all annelid families are represented, as the position of many taxa still remains unresolved. The monophyletic class Clitellata is nested within the paraphyletic polychaetes. Branches highlighted in color indicate families with reported bioluminescent representatives. Colors are indicative of the general color emitted by species within that family. 


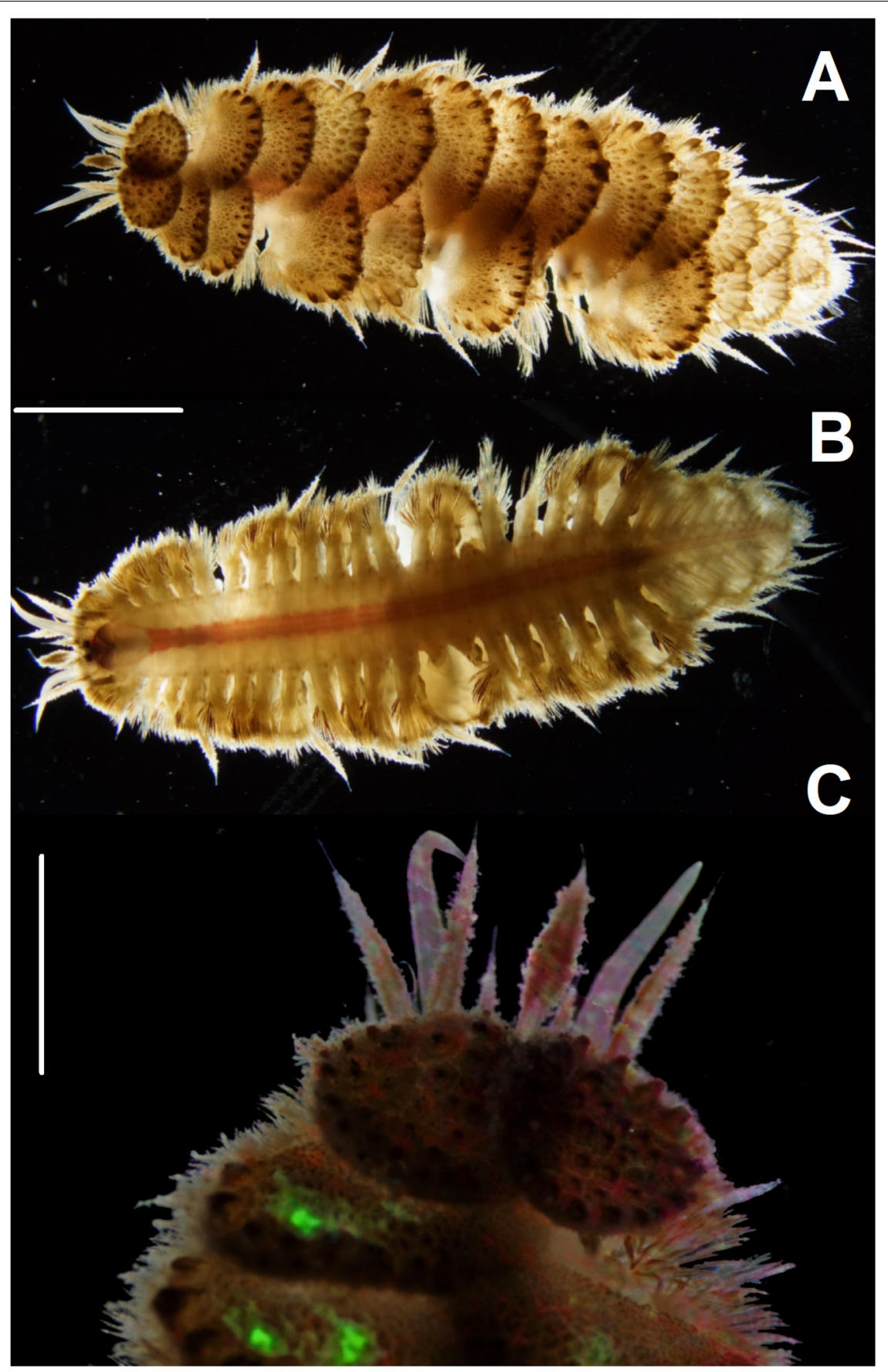

FIGURE 2 | Images of Harmothoe sp. collected in the South Atlantic (Brazilian coastline, southern region) photographed with a stereomicroscope Zeiss SV-11 coupled with a Sony a7s digital camera. (A) dorsum with elytra, (B) ventral view and (C) anterior region displaying green bioluminescence by mechanical stimulation. Scale bars: $(\mathbf{A}, \mathbf{B})=0.5 \mathrm{~cm}$ and $\mathbf{( C )}=0.25 \mathrm{~cm}$. Photos: Álvaro Migotto, Anderson G. Oliveira, and Gabriela V. Moraes. Images were processed using Adobe Photoshop CC.

of paired eyes (Hutchings, 2000). Posteriorly, their pygidium is adorned with one pair of elongated simple anal cirri.

Polynoids have separate sexes and reproduce by broadcast spawning or internal fertilization (Daly, 1972; Van Dover et al., 1999). Daly (1972) described the reproductive strategy of Harmothoe imbricata, where oocytes are directly fertilized by males attaching to the dorsum of females. Sperm moves along ciliated tracts, reaching the gelatinous egg masses attached to the underside of the elytra of the female. Embryos remain protected underneath elytra during early stages of development prior to entering the planktonic stage as trochophore larvae. Polynoid larvae lack the traditional feeding mechanism of a 
metatroch and food groove, but rather utilize elongated oral cilia to capture food (Phillips and Pernet, 1996). So far to date, there have been no descriptions of bioluminescence playing a role in the reproduction or development of $H$. imbricata. A few studies have looked at the reproduction and dispersal mechanism of deep sea polynoids, due to the isolated nature of their habitats (Van Dover et al., 1999; Jollivet et al., 2000). As mentioned, most polynoids display a green luminescence, which is rarely found in the deep sea. The only bioluminescent deep sea polynoid reported to date is the commensal Neopolynoe chondrocladiae mentioned above. A comparison of luminescent pathways between this deep sea species and shallow-water polynoids could provide interesting insights into the evolution of bioluminescence in this group.

Annelids are known to luminesce in three colors: yellow, blue, and green. Figure 1 suggests that there are several independent origins of bioluminescence within annelids, indicating that there is no single overarching mechanism for annelid bioluminescence, which limits how much knowledge is transferrable from one system to another (Haddock et al., 2010). Yellow luminescence is rare and is found in Tomopteris species and several clitellate lineages (Haddock et al., 2010), while green light is the second most common color in annelids and includes the family studied in this review, Polynoidae (Figure 2). A total of 17 polynoid species, representing nine currently recognized genera have been reported as bioluminescent (Supplementary Table 1). Most of these represent the subfamily Polynoinae (as defined by Read and Fauchald, 2020), the single exception being Lepidasthenia stylolepis which represents the subfamily Lepidastheniinae. Blue luminescence can be found in some species of Terebellidae (Dahlgren, 1915; Huber et al., 1989; Kin et al., 2019), Cirratulidae (Petersen, 1999), and Chaetopteridae, specifically in the wellstudied parchment worm, Chaetopterus variopedatus (Harvey, 1952; Huber et al., 1989; Haddock et al., 2010; Branchini et al., 2014; Mirza et al., 2020).

The ecological role of bioluminescence in polychaetes is often seen in the glowing reproductive displays, such as in Odontosyllis luminosa (Gaston and Hall, 2000), however, other displays such as anti-predatory and metabolic processes are also found within the clade (Osborn et al., 2009). Polynoid bioluminescence is most likely linked to a predator avoidance technique of defense and distraction (Bassot and Nicolas, 1995; Haddock et al., 2010). The light is emitted mainly when the animal is provoked or stimulated mechanically (Figure 2; McIntosh, 1874; Fresneau et al., 1984). Concurrently, these animals will autotomize (voluntarily detach) their shiny elytra when stressed or in danger. This combination of released glowing scales allows the organism to escape while their predator is distracted or deterred by the luminescent elytra (Nicol, 1953; Livermore et al., 2018).

\section{BIOCHEMICAL STUDIES ON POLYNOIDAE BIOLUMINESCENCE}

The biochemical study of the process of light emission in Polynoidae is limited to the purification of the polynoidin photoprotein from three species (Malmgrenia lunulata,
Harmothoe imbricata, and Harmothoe areolata) (Plyuscheva and Martin, 2009), as well as some parallel studies conducted in Acholoe squamosa (previously known as Acholoe astericola) (Fresneau et al., 1984). Chemically, bioluminescence is produced by oxidation of a light-emitting molecule (generically called luciferin) catalyzed by enzymes (luciferases), resulting in photons of visible light. In some organisms, the enzyme-substrate complex (luciferin-luciferase) is more stable than its dissociated constituents, being capable of emitting light in proportion to the amount of enzyme present. This complex is called a photoprotein (Shimomura, 1985; Wilson and Hastings, 1998).

However, the real function of the photoprotein polynoidin in the luminescent reaction on Polynoidae remains unknown and has never been fully determined. Additionally, the luciferin involved in this system also remains unknown. Falger (1908) was the first to notice that the light emission in Polynoidae involved a process of oxidation, with an experiment involving bubbling of pure oxygen for $30 \mathrm{~min}$ in seawater containing A. squamosa, resulting in great stimulation of their bioluminescent display. On the contrary, when oxygen was replaced by $\mathrm{CO}_{2}$ in a similar experiment no emission of light was recorded (Harvey, 1952). Harvey tried, without success, to demonstrate the classic luciferin-luciferase reaction from A. squamosa using an extract prepared in the absence of oxygen as a source of luciferin with a cold source of luciferase extract prepared from the scales of the same animal. Furthermore, cross-reactions with luciferin and luciferase extracts from the marine ostracod Vargula hilgendorfii also failed to stimulate the luminescent reaction in vitro (Harvey, 1952). Later, Nicol (1957) recorded a series of spectra of bioluminescence of the polynoidae Harmothoe longisetis, Harmothoe extenuata, Gattyana cirrhosa, and Polynoe scolopendrina which had similar characteristics and $\lambda_{\max }$ at $515 \mathrm{~nm}$.

At the beginning of the 1970s, Herrera and colleagues conducted a series of seminal studies using homogenates prepared from $H$. imbricata and $H$. extenuata (Herrera et al., 1974). The authors corroborated the initial experiments of Harvey and similarly failed to obtain emission of light through the classical hot and cold extract assay (Harvey, 1952; Shimomura, 2006). However, for the first time, they isolated a particulate material that responded by producing light by adding reducing agents such as NADH, NADPH or sodium dithionite. This active material settled as a pellet after $1 \mathrm{~h}$ of centrifugation at 50,000 $\times g$, whereas the supernatant did not produce any light emission. In addition, this activity of luminescence in the pellet was absent by heating, whereby around $50 \%$ of it was lost after $5 \mathrm{~min}$ at $30^{\circ} \mathrm{C}$. Moreover, pellets obtained from the body of these animals or other non-bioluminescent Polynoidae proved to be not active when challenged to the same conditions of stimulation (Herrera et al., 1974).

Initial observations indicated that the light emitted by Polynoidae would be related to the presence of photogenic granules consisting of a combination of microtubules distributed evenly (Bassot, 1966; Bassot et al., 1972; Pavans de Ceccatty et al., 1972a,b). Later on, the first experiments on the purification of this particulate material were conducted (Lecuyer and Arrio, 1975). Attempts to isolate the granules from elytra of $H$. extenuata and 
A. squamosa were performed by centrifugation using a gradient of sucrose, but failed to produce isolates. After centrifugation, the granules were sparsely distributed along the density gradient, and were subsequently destroyed during the process of staining for microscopy experiments. Surprisingly, the authors reported the stimulatory effect of the addition of $\mathrm{Fe}^{2+}$ in the emission of light in vitro of the extracts prepared (Lecuyer and Arrio, 1975).

In the following years, new attempts for the purification of this photogenic material also by means of differential centrifugation were performed (Nicolas, 1979). This time, however, light was detected using sodium dithionite along the sucrose gradient, presenting maximum light emission from two fractions in the range of density from 1.20 to $1.22 \mathrm{~g} / \mathrm{cm}^{3}$. After filtration of the fractions by using $50-\mathrm{kDa}$ molecular weight cutoff filters, protein fractions retained by the filter with $c a .50 \mathrm{kDa}$ showed the highest light emission. The inspection of the fractions with the highest intensity of light produced by electron microscopy revealed the presence of "photosomes," a term used by the authors to describe the structures formed by the endoplasmic reticulum tubules that would be associated to bioluminescence in Polynoidae. Nevertheless, contrary to the results previously described by Herrera and associates (1974), NADH or NADPH did not lead to the emission of light as isolated fractions. The addition of xanthine followed by xanthine oxidase led to the emission of light for several minutes. The partial purification of a protein fraction involved in the process of bioluminescence of Polynoidae was only achieved for the first time by Arrio et al. (1980), by using size exclusion chromatography. During purification, the homogenate was separated into two active fractions with respect to light emission, one of apparent higher molecular weight that eluted in the dead volume, and another one of lower molecular weight, eluted on the 30th fraction collected from the column. The analysis of the active fractions and of the homogenate by SDS-PAGE showed a protein composition virtually identical in comparison to the homogenate and to the higher molecular weight fraction. On the other hand, the light-protein fraction showed a single band, whose retention time was identical to the second band of heavy-protein fraction (Arrio et al., 1980). Fluorescence measurements of those fractions indicated that the light-protein fraction was responsible for the fluorescence band at $540 \mathrm{~nm}$, whereas the maximum emission of fluorescence of heavy-protein fraction was at $515 \mathrm{~nm}$ (excitation at $434 \mathrm{~nm}$ ). Additionally, the fluorescence of heavy-protein fraction matched the fluorescence spectrum of the intact epithelial tissue of luminescent polynoids. According to the authors, both heavy and light fractions are very likely to contain the luciferase that is a peroxidase. This assumption is in the agreement with the light emission observation by the authors when the light-protein reacts with hydrogen peroxide, sodium dithionite, $\mathrm{FeSO}_{4}$ or xanthine/xanthine oxidase. On the other hand, light emission was extinguished by heating, digestion with trypsin or even by the addition of the superoxide dismutase enzyme (Arrio et al., 1980).

Later on, the isolation and purification of a single active component in the luminescent system of these scale worms by working on Malmgrenia lunulata (formerly known as Harmothoe lunulata) was reported (Nicolas et al., 1982). The authors isolated a membrane photoprotein that emitted light peaking at $510 \mathrm{~nm}$ after the addition of Fenton's reagent (generation of hydroxyl radical, $\mathrm{HO}^{\circ}$ ). The maximum value of light emission was very close to the peak at $515 \mathrm{~nm}$ reported earlier for various species of Polynoidae (Nicol, 1957), and was also near to the peak at $520 \mathrm{~nm}$ reported by another group (Lecuyer and Arrio, 1975).

Initially, scales of the annelid Malmgrenia lunulata were homogenized and extracted in the presence of the surfactant Triton X-100 and the soluble fraction obtained was purified by gel filtration and ionic exchange chromatography, yielding a single peak with luminescence activity. The maximum intensity and integral of light emission from this reaction were proportional to the amount of the enriched fraction of protein, thus presenting the characteristics of a bioluminescent system involving a photoprotein. No fluorescence in the green region was detected in the purified protein fraction, when excited at $350 \mathrm{~nm}$, before or after the luminescence reaction occurs. The isolated protein, which received the name of polynoidin, had a molecular weight of $c a .500 \mathrm{kDa}$ and emitted light in response to the addition of reagents that generate either superoxide radical-anion $\left(\mathrm{O}_{2}{ }^{\cdot-}\right)$ or HO (Nicolas et al., 1982). In addition, some experiments suggested the involvement of the $\mathrm{O}_{2}{ }^{-}$in the bioluminescent reaction of these scaly annelids such as the reaction of the purified photoprotein with $\mathrm{KO}_{2}$ in aprotic solvents (DMSO) (Valentine and Curtis, 1975; Nicolas et al., 1982).

At the same time, studies of bioluminescence of Polynoidae of the genus Acholoe as well as attempts for the purification of substances involved in its mechanism of light emission were also performed in parallel by other groups (Bilbaut, 1980a,b; Fresneau et al., 1984). Using homogenates prepared from the scales of $A$. squamosa (formerly known as A. astericola), a fluorescent molecule was isolated through gel filtration chromatography (Fresneau et al., 1984). According to the authors, the isolated compound was likely a chromophoreprotein complex, probably the product of the bioluminescent reaction (its oxyluciferin) with fluorescence emission spectrum very similar to that described previously for the elytra of A. squamosa and $H$. extenuata (Lecuyer and Arrio, 1975). The fluorescence intensity at $520 \mathrm{~nm}$ increased with the addition of either sodium dithionite or xanthine/xanthine oxidase to the homogenate. It is important to emphasize that, similarly to the experiments described for other luminescent polynoid species of the genus Harmothoe, all reagents that yield light emission upon reaction with the isolated protein complex were well-known to generate $\mathrm{O}_{2}{ }^{-}$. Despite the apparent similarities between the bioluminescent systems of Polynoidae of the genera Acholoe and Harmothoe, further studies are still needed to confirm such assumptions.

In the following decades only a few additional works involving Polynoidae bioluminescent systems were published, being limited primarily to polynoidin applications like the probe for determination of $\mathrm{O}_{2}{ }^{-}$released by macrophages and neutrophils (Colepicolo et al., 1990) or leukocytes (Bassot and Nicolas, 1995). Later on, Plyuscheva and Martin (2009) isolated and purified the polynoidin protein with $80 \%$ homology between $H$. imbricata and $H$. areolata. They used hypoxanthine/xanthine oxidase to trigger the light emission in the extracts, similar to was performed earlier (Nicolas, 1979; Arrio et al., 1980). Nevertheless, the reaction between $\mathrm{O}_{2}{ }^{-}$and polynoidin radicals in these organisms did not seem to depend on any other compounds 
of low molecular weight, suggesting that polynoidin bears a covalent-bound cofactor (Plyuscheva et al., 2006). Interestingly, the isolated photoproteins presented molecular weight around 65-66.5 $\mathrm{kDa}$, which indicates that the previously reported value of $500 \mathrm{kDa}$ (Nicolas et al., 1982) was related to the aggregation with other proteins, similarly to what occurs in other bioluminescent systems (Takahashi and Isobe, 1994; Ballou et al., 2000; Shimomura, 2006; Galeazzo et al., 2019). Plyuscheva and Martin (2009) also detected polynoidin in two nonbioluminescent species of scale worms, Lepidonotus squamatus and L. clava. According to them, the presence of polynoidin in non-luminescent species suggests an ancient function of this protein that has been lost and replaced by a mechanism capable of quenching $\mathrm{O}_{2} \cdot-$, thereby playing a protective role against oxidative stress. This would explain why non-luminescent worms have a longer lifetime by saving energy previously used in the production of light and direct it to other defensive strategies (Plyuscheva and Martin, 2009).

Finally, with the exception of the remarkable presence of a photoprotein that seems to use $\mathrm{O}_{2}{ }^{-}$to produce light, the molecular study of the light emission in this family of annelids remains open, lacking the isolation of its luciferin and oxyluciferin as well as potential cofactors involved in the biochemical pathway that leads to bioluminescence.

\section{FUTURE DIRECTIONS}

Polynoidae is one of the most diverse polychaete families. Currently, bioluminescence is primarily known from members of the subfamily Polynoinae (as circumscribed by Read and Fauchald, 2020), although this group may not even be monophyletic (Norlinder et al., 2012; Gonzalez et al., 2018). A single representative of the subfamily Lepidastheniinae (Lepidasthenia stylolepis) has been reported as bioluminescent (Nicol, 1953), but this record is difficult to verify. To understand the evolution of bioluminescence in scale worms, one needs to carefully examine more species belonging to different polynoid subclades and achieve higher resolution of their phylogenetic relationships. The most plausible ecological explanation for scale worm bioluminescence is predator deterrence, but other possible functions cannot be ruled out. There are currently no reports on the bioluminescence of the free-swimming larvae, but rearing experiments would be necessary to confirm when bioluminescence starts ontogenetically. Even though a number of bioluminescent polynoids are known, the chemical mechanism of light emission in these organisms is not clearly understood. Cell-free extracts prepared from scales produce light upon the addition sodium dithionite, hydrogen peroxide/ferrous ions and the xanthine-xanthine oxidase system. A photoprotein named polynoidin was partially purified from Malmgrenia lunulata,

\section{REFERENCES}

Andrews, E. A. (1891). Report upon the annelida polychaeta of Beaufort, North Carolina. Proc. U. S. Natl. Mus. 14, 277-302. doi: 10.5479/si.00963801.14852.277
Harmothoe imbricata and $H$. areolata and, like the cell-free extracts of the scales, polynoidin was able to emit green light peaking at $515 \mathrm{~nm}$ in the presence of reactive oxygen species. However, the photoprotein structure and properties, the luciferin chemical nature and the light-emitting reaction involved in this system are still unclear. Preliminary results obtained by our group using polynoids of the Harmothoe genus, collected in Southeastern Brazil, corroborated most of the previous reports. Additionally, we are currently working on polynoidin purification and related biochemical studies. We expect that the elucidation of the biochemical pathway involved in bioluminescent can contribute to the understanding the ecology of polynoids and help toward the development of biotechnological tools. As many photoproteins found in bioluminescent organisms are currently used as luminescent probes in clinical assays, it is not unrealistic to consider the system herewith described as a serious candidate to detect reactive oxygen species.

\section{AUTHOR CONTRIBUTIONS}

DS and CS wrote and reviewed the drafts of the manuscript and approved the final manuscript. GM, MCH, AS, and AO collected and analyzed the literature, produced the tables and figures, wrote and reviewed the drafts of the manuscript, and approved the final manuscript. All authors contributed to the article and approved the submitted version.

\section{FUNDING}

Funding for this project was provided by the São Paulo Research Foundation (FAPESP) (AO, DS, and CS 2017/22501-2, AO 2018/22304-5 and 2020/07600-7, GM 2019/25086-1, and DS 2019/12605-0) and TAMU FAPESP Collaborative Grant Program (project number: 2018-3-09) which supported AS and $\mathrm{MCH}$.

\section{ACKNOWLEDGMENTS}

We wish to thank Álvaro E. Migotto from Center for Marine Biology (University of São Paulo, Brazil) for assistance in filming and photographing the bioluminescent scale worms.

\section{SUPPLEMENTARY MATERIAL}

The Supplementary Material for this article can be found online at: https://www.frontiersin.org/articles/10.3389/fmars. 2021.643197/full\#supplementary-material

Arrio, B., Dupaix, A., Fresneau, C., Lecuyer, B., Lescure, N., and Volfin, P. (1980). Purification de l'emetteur de fluorescence chez les polynoinae (annelides polychetes). C. R. Acad. Sci. Paris Ser. D. 290, 1537-1540.

Ballou, B., Szent-Gyorgyi, C., and Finley, G. (2000). "Properties of a new luciferase from the copepod Gaussia princeps," in Proceedings of the 
11th International Symposium on Bioluminescence and Chemiluminescence, (Asilomar, CA).

Bassot, J. M. (1966). Une forme microtubulaire et paracristalline de reticulum endoplasmique dans les photocytes des Annelides Polynoinae. J. Cell Biol. 31, 135-158. doi: 10.1083/jcb.31.1.135

Bassot, J. M., Bilbaut, A., and Pavans de Ceccatty, M. (1972). Fluorescence primaire des paracristaux de reticulum-endoplasmique dans les cellules lumineuses de l'Annélide Acholoe astericolla delle Ch. C. R. Acad. Sci. Paris Ser. D. 275, 2687-2690.

Bassot, J. M., and Nicolas, M. T. (1995). Bioluminescence in scale-worm photosomes: the photoprotein polynoidin is specific for the detection of superoxide radicals. Histochem. Cell Biol. 104, 199-210. doi: 10.1007/ BF01835153

Bilbaut, A. (1980a). Cell junctions in the excitable epithelium of bioluminescent scales on a polynoid worm: a freeze-fracture and electrophysiological study. J. Cell Sci. 41, 341-368.

Bilbaut, A. (1980b). Excitable epithelial cells in the bioluminescent scales of a polynoid worm; effects of various ions on the action potentials and on the excitation-luminescence coupling. J. Exp. Biol. 88, 219-238.

Branchini, B. R., Behney, C. E., Southworth, T. L., Rawat, R., and Deheyn, D. D. (2014). Chemical analysis of the luminous slime secreted by the marine worm Chaetopterus (Annelida, Polychaeta). Photochem. Photobiol. 90, 247-251. doi: 10.1111/php.12169

Britayev, T. A. (1991). "Life cycle of the symbiotic scale-worm Arctonoe vittata (Polychaeta: Polynoidae) in the Systematics, Biology and Morphology of World Polychaeta," in Proceedings of the 2nd International Polychaeta Conference, Vol. Ophelia Suppl., 5, eds M. E. Petersen and J. B. Kirkegaard, Copenhagen 305-312.

Colepicolo, P., Camarero, V. M., Nicolas, M. T., Bassot, J. M., Karnovsky, M. L., and Hastings, J. W. (1990). A sensitive and specific assay for superoxide anion released by neutrophils or macrophages based on bioluminescence of polynoidin. Anal. Biochem. 184, 369-374. doi: 10.1016/0003-2697(90) 90695-6

Dahlgren, U. (1915). The production of light by animals. J. Franklin Inst. 180, 513-537. doi: 10.1016/S0016-0032(15)90523-9

Daly, J. M. (1972). The maturation and breeding biology of Harmothoë imbricata (Polychaeta: Polynoidae). Mar. Biol. 12, 53-66. doi: 10.1007/bf003 47429

Falger, F. (1908). Untersuchungen über das Leuchten von Acholoe astericola. Biol. Centrbl. 23, 641-649.

Fresneau, C., Arrio, B., Lecuyer, A., Dupaix, N., Lescure, N., and Volfin, P. (1984). The fluorescent product of scaleworm bioluminescent reaction: an in vitro study. Photochem. Photobiol. 39, 255-261. doi: 10.1111/j.1751-1097. 1984.tb03435.x

Galeazzo, G. A., Mirza, J. D., Dorr, F. A., Pinto, E., Stevani, C. V., Lohrmann, K. B., et al. (2019). Characterizing the bioluminescence of the humboldt squid, dosidicus gigas (d'Orbigny, 1835): one of the largest luminescent animals in the world. Photochem. Photobiol. 95, 1179-1185. doi: 10.1111/php.13106

Gaston, G., and Hall, J. (2000). Lunar periodicity and bioluminescence of swarming Odontosyllis luminosa (Polychaeta: Syllidae) in Belize. Gulf Caribb. Res. 12, 47-51. doi: 10.18785/gcr.1201.07

Gonzalez, B. C., Martínez, A., Borda, E., Iliffe, T. M., Eibye-Jacobsen, D., and Worsaae, K. (2018). Phylogeny and systematics of aphroditiformia. Cladistics 34, 225-259. doi: 10.1111/cla.12202

Haddock, S. H. D. (2006). "Luminous marine organisms," in Photoproteins in Bioanalysis, eds S. Daunert and S. K. Deo (New York, NY: Wiley-VCH), 25-47.

Haddock, S. H. D., Moline, M. A., and Case, J. F. (2010). Bioluminescence in the Sea. Ann. Rev. Mar. Sci. 2, 443-493. doi: 10.1146/annurev-marine-120308081028

Hartman, O. (1978). Polychaeta from the Weddell Sea quadrant, Antarctica. Antarctic Res. Ser. 26, 125-217. doi: 10.1029/ar026p0125

Harvey, E. N. (1952). Bioluminescence. New York, NY: Academic Press.

Harvey, E. N. (1957). A History of Luminescence From the Earliest Times Until 1900. Philadelphia, PA: The American Philosophical Society.doi: 10.5962/bhl. title. 14249

Herrera, A. A. (1979). Electrophysiology of bioluminescent excitable epithelial cells in a polynoid polychaete worm. J. Cell Biol. 129, 67-78. doi: 10.1007/ BF00679913
Herrera, A. A., Hastings, J. W., and Morin, J. G. (1974). Bioluminescence in cell free extracts of the scale worm Harmothoe (Annelida, Polynoidae). Biol. Bull. 147, 480-481.

Herring, P. J. (1983). The spectral characteristics of luminous marine organisms. Proc. R. Soc. Lond. B Biol. Sci. 220, 183-217. doi: 10.1098/rspb.1983. 0095

Herring, P. J. (1987). Systematic distribution of bioluminescence in living organisms. J. Biolumin. Chemilumin. 1, 147-163. doi: 10.1002/bio.11700 10303

Huber, M. E., Arneson, A. C., and Widder, E. A. (1989). Extremely blue bioluminescence in the polychaete Polycirrus perplexus (Terebellidae). Bull. Mar. Sci. 44, 1236-1239.

Hutchings, P. A. (2000). "Family polynoidae," in Polychaetes and Allies: The Southern Synthesis, eds P. L. Beesley, G. J. B. Ross, and C. J. Glasby (Melbourne, VIC: CSIRO Publishing), 152-157.

Jollivet, D., Empis, A., Baker, M. C., Hourdez, S., Comtet, T., Jouin-Toulmond, C., et al. (2000). Reproductive biology, sexual dimorphism, and population structure of the deep sea hydrothermal vent scale-worm, branchiplynoee seepensis (Polychaeta: Polynoidae). J. Mar. Biol. Ass. U.K. 80, 55-68. doi: $10.1017 / \mathrm{s} 0025315499001563$

Kin, I., Jimi, N., and Oba, Y. (2019). Bioluminescence properties of Thelepus japonicus (Annelida: Terebelliformia). Luminescence 34, 602-606. doi: 10.1002/ bio. 3643

Kotlobay, A. A., Dubinnyi, M. A., Purtov, K. V., Guglya, E. B., Rodionova, N. S., Petushkov, V. N., et al. (2019). Bioluminescence chemistry of fireworm Odontosyllis. Proc. Natl. Acad. Sci. U.S.A. 116, 18911-18916. doi: 10.1073/pnas. 1902095116

Lecuyer, B., and Arrio, B. (1975). Some spectral characteristics of the light emitting system of the polynoid worms. Photochem. Photobiol. 22, 213-215. doi: 10.1111/ j.1751-1097.1975.tb06738.x

Livermore, J., Perreault, T., and Rivers, T. (2018). Luminescent defensive behaviors of polynoid polychaete worms to natural predators. Mar. Biol. 165, 149. doi: 10.1007/s00227-018-3403-2

Martin, D., and Britayev, T. A. (1998). Symbiotic polychaetes: review of known species. Oceanogr. Mar. Biol. Ann. Rev. 36, 217-340.

Martin, D., and Britayev, T. A. (2018). Symbiotic polychaetes revisited: an update of the known species and relationships (1998-2017). Oceanogr. Mar. Biol. Ann. Rev. 56, 371-448. doi: 10.1201/9780429454455-6

Martini, S., and Haddock, S. H. D. (2017). Quantification of bioluminescence from the surface to the deep sea demonstrates its predominance as an ecological trait. Sci. Rep. 7:45750. doi: 10.1038/srep45750

McIntosh, W. C. (1874). VII. On British Annelida. Trans. Zool. Soc. London. 9, 371-394. doi: 10.1111/j.1096-3642.1976.tb00243.x

Mirza, J. D., Migotto, A. E., Yampolsky, I. V., de Moraes, G. V., Tsarkova, A. S., and Oliveira, A. G. (2020). Chaetopterus variopedatus bioluminescence: a review of light emission within a species complex. Photochem. Photobiol. 96, 768-778. doi: $10.1111 / \mathrm{php} .13221$

Mitani, Y., Yasuno, R., Futahashi, R., Oakley, T. H., and Ohmiya, Y. (2019). Luciferase gene of a Caribbean fireworm (Syllidae) from Puerto Rico. Sci. Rep. 9:13015. doi: 10.1038/s41598-019-49538-7

Moline, M. A., Oliver, M. J., Mobley, C. D., Sundman, L., Bensky, T., Bergmann, T., et al. (2007). Bioluminescence in a complex coastal environment: 1. Temporal dynamics of night-time water-leaving radiance. J. Geophys. Res. Oceans 112, 1978-2012. doi: 10.1029/2007JC004138

Nicol, J. A. C. (1953). Luminescence in polynoid worms. J. Mar. Biol. Ass. U.K. 32, 65-84. doi: 10.1017/S0025315400011437

Nicol, J. A. C. (1957). Spectral composition of the light of polynoid worms. J. Mar. Biol. Ass. U.K. 36, 529-538. doi: 10.1017/S0025315400025820

Nicolas, M. T. (1979). Presence de photosomes dans les fractions lumineuses du système elytral des Polynoinae (Annelides, Polychetes). C. R. Acad. Sci. Paris 289, 177-180.

Nicolas, M. T., Bassot, J. M., and Shimomura, O. (1982). Polynoidin, a membrane photoprotein isolated from the bioluminescent system of scaleworms. Photochem. Photobiol. 35, 201-207. doi: 10.1111/j.1751-1097.1982. tb03832.x

Norlinder, E., Nygren, A., Wiklund, H., and Pleijel, F. (2012). Phylogeny of scale-worms (Aphroditiformia, Annelida), assessed from 18SrRNA, 28SrRNA, 16SrRNA, mitochondrial cytochrome $c$ oxidase subunit I (COI), and 
morphology. Mol. Phylogenet. Evol. 65, 490-500. doi: 10.1016/j.ympev.2012. 07.002

Oba, Y., Stevani, C. V., Oliveira, A. G., Tsarkova, A. S., Chepurnykh, T. V., and Yampolsky, I. V. (2017). Selected least studied but not forgotten bioluminescent systems. Photochem. Photobiol. 93, 405-415. doi: 10.1111/php. 12704

Osborn, K. J., Haddock, S. H. D., Pleijel, F., Madin, L. P., and Rouse, G. W. (2009). Deep-Sea, swimming worms with luminescent "bombs". Science 325:964. doi: 10.1126/science. 1172488

Panceri, P. (1875). La luce e gli organi luminosi di alcuni annelidi. Atti Accad. Sci. Napoli 7, 1-20.

Pavans de Ceccatty, M., Bassot, J. M., Bilbaut, A., and Nicolas, M. T. (1972a). Genèse des paracristaux photogènes et de leurs structures d'excitation dans les cellules de l'élytre d'Acholoe astericola Delle Ch. C. R. Acad. Sci. Paris 275, 2363-2366.

Pavans de Ceccatty, M., Bilbaut, A., and Bassot, J. M. (1972b). ‘. C. R. Acad Sci Paris 275, 2523-2526.

Petersen, M. E. (1999). Reproduction and development in Cirratulidae (Annelida: Polychaeta). Hydrobiologia 402, 107-128. doi: 10.1023/A:10037364 08195

Pettibone, M. H. (1989). New species of scale-worms (Polychaeta: Polynoidae) from the hydrothermal rift-area of the mariana back-arc basin in the Western Central Pacific. Proc. Biol. Soc. Wash. 102, 137-153.

Phillips, N. E., and Pernet, B. (1996). Capture of large particles by suspensionfeeding scaleworm larvae (Polychaeta: Polynoidae). Biol Bull. 191, 199-208. doi: $10.2307 / 1542923$

Pieribone, V., and Gruber, D. (2006). A Glow in the Dark: The Revolutionary Science of Biofluorescence. Cambridge MA: Belknap Press.

Plyuscheva, M., Manukhov, I., and Vissokikh, M. (2006). "Peculiarities of luminescence of Harmothoe imbricata," in Proceedings of the Xth Scientific Conference of White Sea Biological Station of Moscow State University, ed. A. B. Tzetlin, Moscow, 99-103. [In Russian].

Plyuscheva, M., and Martin, D. (2009). On the morphology of elytra as luminescent organs in scale-worms (Polychaeta, Polynoidae). Zoosymposia 2, 379-389. doi: 10.11646/zoosymposia.2.1.26

Read, G., and Fauchald, K. (2020). World Polychaeta Database. Polynoidae Kinberg, 1856. Available online at: http://www.marinespecies.org/aphia.php?p= taxdetails\&id=939 (accessed December 1,2020$)$

Rouse, G. W., and Pleijel, F. (2001). “Aphroditoidea malmgren. 1867," in Polychaetes, eds G. W. Rouse and F. Pleijel (New York, NY: Oxford University Press), 73-76.

Shimomura, O. (1985). Bioluminescence in the sea: photoprotein systems. Symp. Soc. Exp. Biol. 39, 351-372.
Shimomura, O. (2006). Bioluminescence. Singapore: World Scientific Publishing Co. Pte. Ltd.

Taboada, S., Silva, A. S., Díez-Vives, C., Neal, L., Cristobo, J., Ríos, P., et al. (2020). Sleeping with the enemy: unravelling the symbiotic relationships between the scale worm Neopolynoe chondrocladiae (Annelida: Polynoidae) and its carnivorous sponge hosts. Zool. J. Linnean Soc. [Preprint] doi: 10.1093/ zoolinnean/zlaa146

Takahashi, H., and Isobe, M. (1994). Photoprotein of luminous squid, Symplectoteuthis oualaniensis and reconstruction of the luminous system. Chem. Lett. 23, 843-846. doi: 10.1246/cl.1994.843

Valentine, J. S., and Curtis, A. B. (1975). A convenient preparation of solutions of superoxide anion and the reaction of superoxide anion with a copper (II) complex. J. Am. Chem. Soc. 97, 224-226. doi: 10.1021/ja00834a058

Van Dover, C. L., Trask, J., Gross, J., and Knowlton, A. (1999). Reproductive biology of free-living and commensal polynoid polychaetes at the lucky strike hydrothermal vent field (Mid-Atlantic Ridge). Mar. Ecol. Prog. Ser. 181, 201214. doi: $10.3354 /$ meps 181201

Verdes, A., and Gruber, D. F. (2017). Glowing worms: biological, chemical, and functional diversity of bioluminescent annelids. Integr. Comp. Biol. 57, 18-32. doi: 10.1093/icb/icx017

Weigert, A., Helm, C., Meyer, M., Nickel, B., Arendt, D., Hausdorf, B., et al. (2014). Illuminating the base of the annelid tree using transcriptomics. Mol. Biol. Evol. 31, 1391-1401. doi: 10.1093/molbev/msu080

Widder, E. A. (2010). Bioluminescence in the ocean: origins of biological, chemical, and ecological diversity. Science 328, 704-708. doi: 10.1126/science.1174269

Wilson, T., and Hastings, J. W. (1998). Bioluminescence. Annu. Rev. Cell Dev. Biol. 14, 197-230. doi: 10.1146/annurev.cellbio.14.1.197

Zhang, Y., Sun, J., Rouse, G. W., Wiklund, H., Pleijel, F., Watanabe, H. K., et al. (2018). Phylogeny, evolution and mitochondrial gene order rearrangement in scale worms (Aphroditiformia, Annelida). Mol. Phylogenet. Evol. 125, 220-231. doi: 10.1016/j.ympev.2018.04.002

Conflict of Interest: The authors declare that the research was conducted in the absence of any commercial or financial relationships that could be construed as a potential conflict of interest.

Copyright (c) 2021 Moraes, Hannon, Soares, Stevani, Schulze and Oliveira. This is an open-access article distributed under the terms of the Creative Commons Attribution License (CC BY). The use, distribution or reproduction in other forums is permitted, provided the original author(s) and the copyright owner(s) are credited and that the original publication in this journal is cited, in accordance with accepted academic practice. No use, distribution or reproduction is permitted which does not comply with these terms. 